\title{
The Centre and the Periphery: Productivity and the Global Networked Public Sphere
}

\author{
Peter Sekloča
}

\author{
Department of Communication and Media, Faculty of Humanities, University of \\ Primorska, Koper, Slovenia, peter.sekloca@fhs.upr.si, http://www.fhs.upr.si/en
}

\begin{abstract}
The author examines consequences of expansion strategies of commercial network media, and compares them to ideals of open and accessible public communication. These strategies level out the falling rates of profits that the increased productivity of labour is bringing. Counter-measures of media industries manipulate the amounts of variable and constant capital (outsourcing of labour, shifting of depreciation costs on users, and specialisation). These processes, which are specific to platform business models, ultimately give rise to fragmentation, individualisation and ideological homogenisation of the peripheral public. The public becomes ideologically similar to the centres of power, whereas its critical potential and, consequently, its effective political freedom decreases. While both the political and the economic subsystems and the public alike use network communication to organise their activities, interaction between the two social domains (the system and the lifeworld) resembles an 'interactive top-down communication structure'. Inclusion of citizens-consumers into the productivity race renders interactivity similar to one-way communication.
\end{abstract}

Keywords: centre and periphery, networked public sphere, international communication, network media, platforms, labour, productivity, law of the tendency of the rate of profit to fall, imperialism.

\section{The Centre and the Periphery}

There is broad agreement among many researchers that forms of communication flows, social relations of all kinds, and organisational structures nowadays resemble interactive distributed networks (Benkler 2006; Castells 1996; 2009; Galloway 2004). However, does network-like, interactive communication preclude hierarchical, topdown forms of communication? In what way do network media change the relations between the (global) "centre" and the "periphery" of the (global) public sphere, and the corresponding gap between "haves" and "have nots", of which Masmoudi (quoted in Thussu 2005, 49), a member of the MacBride Commission, warned years ago? Does interactivity by default entail reciprocity? Here, we are concerned with the openness and accessibility of the "networked public sphere" (Benkler 2006) and the political empowerment of citizens that publicly discuss issues of common interest and form their more or less consensual public opinion.

Jürgen Habermas first used the expression "the public sphere" (1989a/1962) to denote the social space in which "non-public opinions" of citizens are mediated by critical publicity (Habermas 1989a/1962, 271): "The public sphere forms the loosely structured periphery to the densely populated institutional centre of the state, and is rooted in turn in the still more fleeting communicative networks of civil society" (Habermas 2009, 159). Media are the infrastructure of the public sphere, whereas the public needs media to produce symbolic representations of the public itself and to exert political influence. Commercial media are bound to laws and strategies of capital 
accumulation, whereas audiences that are also citizens are commercial media's main product (Smythe 1995). Audiences are sold to advertisers and work for them; at the same time they produce new users. The present analysis will address the network media, which consist of the symbiotically-connected "technology-based media" platforms and "content-based media" (Möller and von Rimscha 2017, 39). The question is whether the interactive connection of the peripheral public to the centre can be explained by the contradiction that is put in motion by endeavours to increase productivity of network media.

Researchers rarely combine the objective demands to increase productivity with public sphere theory. Much research has been conducted into how exactly media adapt their operations to the imperatives of capital (Curran 2000), or how they transnationalise their (imperialistic) activities (Thussu 2005; Fuchs 2010). However, researchers seldom directly specify how one of the basic contradictions of the capitalist mode of production - the tendency of the rate of profit to fall (TRPF) (Marx 1948/1894, 177-196), which is the consequence of increased productivity, affects the performance of digital media. Strategies with which media are systematically trying to include citizens-consumers in economic social relations are worth researching exactly because through such inclusion, the public inevitably becomes the addressee of the economic system as well. A clash between two opposing principles comes to the fore: "one operating according to marginal productivity, or what is revealed as merit by a 'free play of market forces', and the other based on social need or entitlement, as certified by the collective choices of democratic politics" (Streeck 2016, 75). This is the clash between particularistic (private) and universalistic (public) principles.

The present thesis is that in the productivity race the network media induce usersproducers to maintain the most optimal combination of variable and constant capital, thus preventing the rates of profit from falling. The prolocutors of the "networked public sphere" (Benkler 2006) do not consider that economic forces make periphery ideologically similar to the centre of political and economic power. Interactivity is promoted as liberating, whereas the reciprocity of exchanges is a guiding principle for industrial actors only.

Years ago, David Harvey pointed to the problem scientists have when they try to overlap "geographical" and "social" "imagination" (1993/1973, 23-24). A transnational focus will serve to explain the politico-economic factors that make both types of "imagination" conceptually overlap. The relations between the centre and the periphery do not only illustrate always-unequal power relations as in Habermas's theory of the public sphere, but also explain the consequences of 'new participatory' business models for the geographical/social realities.

Critical political-economic theory explains fundamental strategies with which the media fight against the "law of the tendency of the rate of profit to fall" (LTRPF) and induce corresponding "counteracting influences" (Marx 1948/1894, 197-205). The section after this introduction addresses problems of interactivity and the networked organisational structure of media. In the third section, we analyse the consequences of the manipulation of variable and constant capital in the form of outsourcing and specialisation. The fourth section explains how interactivity, dominated by exchange relations, imposes a tendency towards an interactive top-down communication structure in all three layers of the social communication structure that comprises "content and communication services, distribution services and infrastructure" (van Cuilenburg 1999, 186). 


\section{The Networked Public Sphere and its Contradictions}

At the heart of the matter, theories of the public and the public sphere address problems of emancipatory, egalitarian, and participatory forms of citizens' communication. C. W. Mills formulated what are perhaps the most well-known empirical criteria for establishing egalitarian conditions for the political efficiency of public communication. His conceptualisation of the media requires, among other things, that as many people as accept an opinion also express it (Mills 1965, 302). Several decades before him, Bertolt Brecht called for the revamping of radio technology so that everyone would be able to distribute his or her opinions, not only to receive them (Brecht 1932). He described interactivity as a property of the distributed network.

In the early 1970s, Enzensberger summarised Brecht's critique of the application of communication technologies and emphasised the artificially-fabricated contradiction between producers and consumers of socialised media technologies. Media equipment is always also the means of production and the media promote this contradiction economically and administratively (Enzensberger 2003/1970, 266). He proposed collective production in which (amateur) producers are autonomous in their decisions as to how, what, and for whom to create content. The idea was to establish the conditions for socialised production: "Network-like communications models built on the principle of reversibility of circuits might give indications of how to overcome this situation: a mass newspaper, written and distributed by its readers, a video network of politically active groups" (Enzensberger 2003/1970, 267).

Reversibility is exchange. Exchange is interactivity by a different name. Reciprocity is the equal amount of the exchanged quantity, or political influence. Baudrillard criticised Enzensberg's proposed reorganisation of the mass media system and maintained that "reversibility has nothing to do with reciprocity" (Baudrillard 2003/1972, 286). He agreed with Enzensberger that "[i]n its present form, equipment like television or film does not serve communication but prevents it. It allows no reciprocal action between transmitter and receiver; technically speaking, it reduces feedback to the lowest point compatible with the system" (Enzensberger 2003/1970, 262). Reversibility supports the exchange, maintained Enzensberger, whereas Baudrillard argued that the exchange relations are the central generator of ideology. The mass media depoliticise messages and events by intrusion into the political public sphere, and, vice versa, the public sphere is included in the dominant mode of exchange in society. It is not enough to transform the message, which both the receiver or the sender can synchronously do by using interactive media. It is necessary to reunite transmitter and receiver, and, as Baudrillard argued, summarising Umberto Eco's argumentation, in this way to "modify the reading codes, to impose other interpretive codes" (Baudrillard 2003/1972, 287). Only the transgression of the present socio-economic relations between media and citizens can establish the basis for reciprocity between equals.

Enzensberger's argumentation follows the emancipatory paradigm by which social change (revolution) may be enacted when the masses seize the media. Baudrillard warns that this is quite a linear understanding of the communication process. The exchange of positions is not enough, because the media have already built reversibility (and not reciprocity) into their own structures: "Doubtless it is for this deeper reason that cybernetic systems today understand perfectly well how to put this complex regulation and feedback to work without affecting the abstraction of the process as a whole or allowing any real 'responsibility' in exchange" (Baudrillard 2003/1972, 286). Baudrillard argued that in the future the surveillance megasystems (police) would integrate the media "metasystems of control by means of feedback and autoregulation. 
[...] In a way, they realize the ideal one might refer to as decentralized totalitarianism" $(2003 / 1972,286)$. It seems that he envisioned the processes by which audiences are the providers of their own data, whereas at the same time they become politically irrelevant producers of amateur content.

Despite being critical of Enzensberger's technological determinism, Baudrillard did not get away from it. By his words, social change could be brought about only by a radical break from the linear understanding of the communication process. The tactic he proposes is the continuous deconstruction of the dominant code, as graffiti can do. However, Baudrillard's idea is quite deterministic: social change could be spurred on by altering the technological structure.

Enzensberger was more practical, Baudrillard more ambiguous, in offering solutions that could undermine the dominance of mass media. Despite the shortcomings, their approaches still offer useful guidelines to the materialist analysis of networked media and the networked public sphere. Enzensberger $(2003 / 1970,261)$ grounds the media in an economic base that shapes our consciousness. Already in the 1970s Baudrillard had warned us that the lifeworld can be colonised with the help of productive audiences, as I call them. Such audiences, besides being sold to advertisers, produce content with their labour power.

Productive audiences are in a contradictory position. First, with their own equipment (hardware and software) they produce content and new users. They are part of the forces of production that are antagonistic to social and economic relations, enabling the exploitation of living labour. In Marxist economics, the two couplets make the capitalist mode of production, which is imbued with contradictions. However, the meaning of the content that users produce is of minor importance for social media corporations, which seize, process and sell information about the "prosumer commodity" (Fuchs 2012, 143-144).

The second contradiction demarcates the ambivalent position of the peripheral public. Its members are at the same time citizens, consumers, employees and clients of the state - to mention the four roles Habermas (1989b, 321-322) counts as relevant to describe the relations between the system and the lifeworld. When members of the public discuss public issues, they perform the role of citizens. They exert political influence on the centre of the political system. Consumers and employees, in our case productive audiences, perform their roles in the private sphere. They exchange money and labour with the economic system. Value orientations, preferences and cultural values shape the role of the consumer and the employee, which means that their performance cannot be forced by sanctions, but can be induced by money, rewards or by persuasive symbolic content. Audiences are induced to perform their role by the promise to obtain free communication channels. Habermas says that demand and political orientations (critical publicity) cannot be bought or collected as labour power and taxes (Habermas 1989b, 322). This holds true only where the system has not colonised the lifeworld. Where social power is non-transparently converted into political influence and combined with economic and "media power", which is "based on the technology and infrastructure of mass communication" (Habermas 2009, 168), promotional publicity substitutes critical publicity. However, Habermas should more widely conceptualise the power of media and consider the rising importance of social media. If nothing else, media power is enhanced when "content-based media" distribute their content over the "technology-based media companies" (Möller and von Rimscha 2017, 39). This couplet of media is forming the main infrastructure of the networked public sphere. Besides media power, one has to mention forms of powers 
that are exercised through media and stem from other subsystems of society (Curran 2003, 148-155).

Through the technological and social networks, the periphery has adopted the "new and important cooperative and coordinate action carried out through radically distributed, non-market mechanisms that do not depend on proprietary strategies" (Benkler 2006, 3). The participants of the socialised "networked information economy" can finally voice their dissent, because production is cheap and the productive sphere accessible to everyone. Here, Benkler does not see the contradiction between the role of the citizen and that of the consumer/producer. Srnicek $(2017,26)$ shows that the platform business models often use is cross-subsidisation: when the price of one product is reduced, the price of the other product is increased. In that manner, information, distributed over the technology-based media, is also subsidised: a common strategy of powerful actors from the political and economic centres. The same holds true for content-based media, which gladly accept "discounted" information from reliable bureaucratic sources (Gandy 1982, 13). The technology-based media might disrupt the power of mass media; however, the process is much more contested then Benkler envisions. Manuel Castells sees the process more dialectically by stating that power and resistance have the same source, namely, the ability and knowledge to switch and to program computer networks (Castells 2009, 47). His approach can sometimes be quite technologically deterministic; however, he is aware that networks by themselves are not leading to horizontal communication. Standards set the "rules to be accepted once in the network. In this case, power is exercised not by exclusion from networks, but by imposition of the rules of inclusion" (Castells 2009, 43). Control has changed, but it has not disappeared. In the past, hierarchical power structures used the centralistic mode of control, which is not suitable to control the networks. Nowadays, platforms have, among other strategies, developed protocological control that uses algorithms, which simultaneously constrain and enable the experiences of users of the electronic networks. Protocol is "a technique for achieving voluntary regulation within a contingent environment" (Galloway 2004, 7). If users are not following the protocols, which are combined to form various algorithms, they experience sanctions, argues Galloway.

Jenkins (2006) also does not consider the contradiction between the forces of production and the relations of production to be detrimental for the open and accessible public sphere. By his words, in the convergence of network technologies and popular culture, citizens are using the tactics they learned when being rebellious consumers $(2006,208)$. Fuchs argues that Jenkins "mistakes politics with popular culture and sees politics taking place largely as micro politics within popular culture" (Fuchs 2014a, 66). Myriad rebellious symbols, stemming from popular culture, are substituting the exchange of arguments. For Jenkins, the standard of critical publicity is not the exchange of arguments, but the symbols that are formed in the sphere, which is dominated by the exchange value. This is far from breaking the dominant code, as Baudrillard had proposed.

The cultural meaning of content might become ideologically effective by granting productive audiences free communication channels as a form of inducement. Fuchs argues that "[c]orporate social media have hijacked the concept of free access and turned it into an ideology that tries to conceal the existence of a mode of capital accumulation based on the commodification of personal data and targeted advertising" (2017, 440). The aim of the current analysis is to delineate material (economic) relations that make this ideology effective. A rough measure of effectivity could be a degree of identification of members of the public with often-reproduced images of the 
life that conforms to the dominant political and consumerist ideals. A historicalmaterialist reading of the network-like social relationships between powerful political/economic centres and peripheries has to consider the historically-specific economic expression of this relationship. Mediated content and produced audiences (themselves material) have historically-specific material relations that are deterministic of a particular - in our case "networked" - social formation (Garnham 1990, 26). In this light, we can distinguish two forms of networked social relations between media and audiences: a) social forms designating the material relations that are commanded by the exchange relations; b) the materially supported symbolic cultural forms that besides being expressions of these material relations are symbolic and allow ideology to enter (Garnham 1990, 26). Exchange relations are sustaining ideological representations of the centre-periphery relations. Ideology becomes effective through inducements and sanctions that the use of the network media brings about.

\section{Productivity and the Periphery}

The object of analysis here is the productivity of the network media that connect the centre of political and economic power with the periphery. These media belong to the "advertising" type of platforms, explains Srnicek (2017). He differentiates between five types of platforms (advertising, cloud, industrial, product and lean platforms). They all have slightly different business models, but they all use data as their basic raw material. In general, platforms are the response to capitalism's constant demand for technological advancement and increased labour productivity (Srnicek 2017, 27). As classical economists David Ricardo and Adam Smith, and especially their critic Karl Marx, have already argued, innovation is a double-edged sword. Innovations gain advantages by increasing labour productivity. However, when competitors adopt innovations, rates of profits begin to fall (Marx 1948/1894, 177-196). Productivity diminishes the exchange value of products, whereas surplus value also falls in proportion to the total capital invested (1948/1894, 178-179). Marx's basic explanation point, stemming from the labour theory of value (LTV), is that an hour of average (socially necessary) labour, independently from productive power variation, "always yields equal amounts of value" $(1947 / 1867,7)$. The means of production (constant capital - c) replaces labour power (variable capital - v), whereby the organic composition of capital (c/v) increases, which, in turn, results in a decreasing rate of profit, ceteris paribus. However, "[t]here must be some counteracting influences at work, which cross and annul the effect of the general law, and which give it merely the characteristic of a tendency, for which reason we have referred to the fall of the general rate of profit as a tendency to fall" (Marx 1948/1894, 197). That is why Marx speaks about the tendential fall of the profit rates.

It is counter to common sense that higher productivity could bring a lower rate of profit. Exactly such an argument has been used many times when economists from various theoretical backgrounds tried to prove that Marx's theory is inconsistent, if not simply wrong. The controversy about the LTRPF has lasted more than a century and is often ideologically fuelled - as in the case of the Nobel Prize laureate Paul A. Samuelson (1971), who in a widely-read article defended bourgeois economics through advising young Marxists to discard the LTV. The academic debate has also been addressing the connection between the LTV and the determination of prices, that is, the transformation of values into production prices. The so-called 'transformation problem' is firmly connected to the LTRPF. Marx (1948/1894, 123), when he was dealing with the 'transformation problem', emphasised that the total surplus value is distributed among sectors according to the proportion of the capital advanced, 
independently from the organic composition of capital. On the global scale, the media and information sector is not among the biggest sectors of the global economy. Fuchs $(2010,40)$ demonstrates that the financial sector has the biggest capital assets, following by the oil and gas sectors, while the information sector is the third. Considering this, the counteracting influences that companies are applying in the media and information sectors cannot divert the falling rates of profits of all the other sectors. To test the theoretical work presented in this article, statistical analysis that would compare the rates of profits of various sectors on a global level is needed.

Dmitriew and Bortkiewicz were among the first that questioned Marx's LTV and the internal consistency of his work at the end of the 19th and the beginning of the 20th century, laying the foundations of the simultaneist-physicalist interpretation (critique) of Marx (Kliman 2007, 41-54). Fierce debate also proceeded in 2013, when Michael Heinrich, a representative of the "new reading of Marx", published an article in the journal Monthly Review, claiming that "the law as such" does not first fall apart because of counteracting factors, but earlier, on the theoretical level, because there is no definite answer of how fast the organic composition of capital might be rising (Heinrich 2013). Many authors (Carchedi and Roberts 2013; Kliman et al. 2013,3) responded by arguing that when Heinrich is talking about the possible consequential rise of the rate of surplus value and of the rate of profit, he is actually considering the effects of the counteracting factors or of the dis-accumulation of capital. I argue elsewhere (Sekloča 2015) that both sides are missing some important dimensions about the LTRPF. They do not consider that counteracting influences also have their limits; that they are contradictory, such that the system does not allow them to be played out in their full reach. Marx $(1948 / 1894,192)$ has predicted such scenarios; however, he didn't devote much attention to them and treated them as isolated cases.

Harvey also argues that the 'law' does not hold universally, which means that it cannot be treated as law. It cannot explain the last crisis that started in 2007-8: "Marx's theory of the falling rate of profit should be treated as a contingent rather than a definitive proposition" (Harvey 2014, 11). In general, Harvey argues that the crisis is the consequence of various factors that all constitute the circulation process of capital. That is why the crisis is always on the move. Harvey's criticism of the LTRPF, published as a draft of an essay, gave an impetus to a lively academic debate. Michael Roberts responded to Harvey about the forced monocausality of the "law" by stating that crises have different "triggers", whereas conceptualisation of capital in LTRPF "starts with the 'general', or should we say with the 'abstract', and proceeds step by step to the concrete" (Roberts 2014). Kliman also responded to Harvey's arguments by stating that Marx "argued that a decline in the rate of profit leads to a crisis indirectly and after some delay. It promotes overproduction (by, e.g., depressing productive investment demand)" (Kliman 2015). Both Roberts and Kliman accentuate that investment demand for cheap constant capital is crucial to prevent the rate of profit from falling; however, the whole process is raising the organic composition of capital. In the long run, the last trend prevails, as empirically proven many times over. ${ }^{1}$

Srnicek defines the three most common fields in which platform firms try to increase the level of productivity and at the same time adopt the strategies to fight the falling

${ }^{1}$ Profits experienced a steep rise during the Second World War and at the end of 1950s a long decline started that lasted until the beginning of 1980 s, when profitability drastically declined and has not recovered ever since - from 1982 to 2001 the rate fell by 26.9 percent, followed by a short but steep recovery trend (the rate was equal as in the 1980s) that lasted until 2006, when a steep fall happened (Kliman 2011, 75-79). During that time the organic composition of capital rose by an annual rate of 1.5 percent on average (Kliman 2011, 133). 
rates of profit: "the adoption of efficient technologies and techniques in the labour process, specialisation, and the sabotage of competitors" (Srnicek 2017, 8). In other words, they achieve their business aims with the manipulation of variable and constant capital, and specialisation. The sabotage of competitors comprises various legal or illegal strategies to enhance network externalities - "the network effects" (Srnicek $2017,26)$, from pre-installed software to actions that diminish network neutrality.

One of the most fruitful ways to describe centre-periphery relations is to consider areas that capital tries to colonise as having "less advanced composition of capital" (McKenzie 1977). I understand less advanced composition of capital as being less productive (due to its lower organic composition):

The societal formation in the periphery can be relatively defined as being a 'less advanced composition' than that in the centre, but both of the modes of economic integration operate under the centre formations conditions, i.e. the conditions of the 'more advanced composition' (McKenzie 1977, 70).

Usually, the periphery has only one major type of good to exchange with the centre, and in the case of public communication, this would be (free) digital labour and personal data.

Analytically, all strategies that, according to Marx (1993/1939, 408; 539; 1948/1894, 197-205), divert the falling rates of profits culminate in the two modes that try to expand the market or to rationalise production. Manipulation of variable capital is characteristic of the first mode; manipulation of constant capital is characteristic of the second mode. Especially, expansion of the (world) market, enhanced exploitation, a relative depression of wages, and the cheapening of constant capital are strategies that network media use to fight the falling rates of profit. Roberts usually accentuates the two key counteracting influences that are most at the level of abstraction of "the law as such": "a rising rate of surplus-value and the cheapening of constant capital" (2014). This leads us down the path of considering strategies of a) outsourcing of creative labour, b) passing depreciation costs of constant capital (software and hardware) on to users, and c) investment into infrastructure to enhance distribution (data centres, optical cables, servers, platforms and so on).

\subsection{Outsourcing of Variable Capital (Labour)}

Here, we should differentiate between technology-based platforms (social media and search engines) and content-based media. If the exchange of labour for physical capital is still a difficulty in professional production, social media have deployed business models that employ free amateur labour. This is one of the main strategies (counteracting influences) to lower costs of labour and to increase surplus labour, i.e., to intensify exploitation and to depress wages. Labouring audiences do not get any financial compensation for their applied labour power, which is the reason why Fuchs $(2012,143)$ argues that the audiences are infinitely exploited.

Professional quality standards do not apply to amateur media production. Nevertheless, the pool of potential users is enormous and easily reachable on a global scale. The exchange proceeds on two tiers: users produce and exchange content to stimulate public discussion: at the same time they (i.e. their data) are the commodity that is exchanged on the industrial market, where platforms and advertisers meet. Reversibility supports a decentralised production of data, whereas the processing of data and access to users worldwide, which advertisers buy from platforms, is centralised. 
Content-based media do not outsource labour directly, but are in symbiosis with technology-based companies that distribute their content, argue Möller and von Rimscha $(2017,45)$. (De)centralisation should be analysed along three dimensions: control over data, business models regarding infrastructure, and content distribution (Möller and von Rimscha 2017, 40-41). Technology-based platforms centralise data collection and have a monopoly in an advertising business. This allows the targeting of audiences for persuasive commercial and political communication. In this setting, "an ongoing centralization of the global informational ecosphere occurs if the contentbased media companies arrange their business models with a view toward the dominant digital media platforms" (Möller and von Rimscha 2017, 41). Production of content is in the networked public sphere, further decentralised as distribution of either professional or amateur content.

Labouring audiences experience commercialisation of the communication sphere that falls into the economic domain of society. Reversibility for both types of network media enables the extraction of data. Users experience reversibility as interactivity between each other, and between themselves and the political and economic centre. Clicktivism and access to various government web pages provide examples of this. Reciprocity exists between users when they exchange content, but not between users and the content-based media or between users and the political centre of the public sphere. However, relations are reciprocal between both types of network media and advertisers.

\subsection{Outsourcing of Constant Capital}

Productive audiences themselves cover part of the investment costs in production and distribution capacities. This is a path towards the cheapening of elements of constant capital, one of the counteracting influences. When users-producers are buying computer hardware and software for their personal use, they themselves are providing, at their own expense, the means of production. First, this provision mitigates the problem of the replacement of labour with capital - the 'Baumol' disease - because both forms of capital are available in infinite quantities. There are practically no restrictions concerning combinations of various amounts of both forms of capital. Consequently, this strategy lowers the organic composition of capital of media companies. Second, in the short run, it soothes the problem caused by the law of diminishing returns. The periphery takes care of both problems.

Lowering the ratio of the organic composition of capital means that relatively less capital is needed for the same amount of labour. Consequently, more constant capital can be invested in other productive activities. Usually those companies that are vertically integrated diversify their range of products or services along different informational subsectors - for example, Facebook also produces virtual reality hardware and storage facilities; Google, alongside running Google+, produces cellular phones, and so on. Information technology departments shift the depreciation costs of constant capital by selling hardware and software (the means of production) to usersproducers. Consequently, they can specialise in building infrastructure, maintaining distribution services, developing new software and platforms, and new algorithms: in short, they can invest in research and development (R\&D) and distribution. Network media companies produce and sell complementary products, enabling them to achieve economies of scale and scope, or to specialise in different sectors. The expansion of production into new subsectors of the information economy, i.e., the widening of their product portfolio, enables corporations to issue new stock shares, which is another counteracting influence that Marx had specified. 
Audiences have always been buying media apparatuses of their own volition. However, digital technology becomes obsolete faster than other technologies. Kliman $(2011,138)$ has stressed that contemporary industrial ICT is abnormally subject to "moral deprecation", as Marx called it. Physical capital does not lose value only due to 'wear and tear', but more importantly due to built-in obsolescence: "It loses exchangevalue, either by machines of the same sort being produced cheaper than it, or by better machines entering into competition with it" (Marx 1947/1867, 346). The average rate of depreciation for all means of production between 1960 and 2000 rose from 7 to 11 percent, but for the information-processing equipment the rate rose from 5 percent to more than 18 percent (Kliman 2011, 141). Users' hardware gets outdated abnormally quickly, while productive audiences bear the costs of such obsolescence of their own hardware. Technology is literally handed down to citizens-consumers, who gratefully grab and pay for new tools. Users are maintaining and expanding the infrastructure of the networked public sphere. They provide reversibility. However, they are also producing new audiences. They are expanding the space in which new data is collected.

The law of diminishing returns states that beyond a certain point of a variable factor (labour), the total marginal product increases in ever-smaller proportions (ceteris paribus). In the short run, the law of diminishing returns causes problems when technology cannot be made compatible with the rising amount of labour easily or fast enough. The circumstances are completely different in the case of amateur production. Free amateur labour, which introduces its own tools into the production process, is abundant. Productive audiences strive of their own accord for an optimal combination of constant and variable capital, which facilitates increasing returns of scale and scope. Due to such characteristics of amateur production, it is reasonable for digital media companies to invest more in $R \& D$, infrastructure, distribution services, and software and hardware.

\subsection{Investment into Infrastructure and Specialisation}

With infrastructure, our analysis comprises all three layers of the social communication system: content and communication services, distribution services and infrastructure. The organic composition of capital of the global periphery is usually low, which opens new opportunities for investment of constant capital in the form of communication infrastructure. In 2013, Facebook reported an investment of 1.36 billion US dollars in data centres, servers, network infrastructure and buildings; in 2014 the investment was 1.83 billion, and in 20152.52 billion US dollars (Data Center Knowledge 2018). In September 2018 Facebook announced the building of a new hyperscale data centre in Singapore, the major Pacific-Asia convergence point for submarine cables, that will equal the total capacity of all the other data centres that platform companies have built in Singapore (Sverdlik 2018). The investment in infrastructure is following the increase in revenues from advertising. Facebook increased its advertising revenue worldwide from 11.5 billion US dollars in 2014 to almost 28 billion US dollars in 2018 (Statista 2018a). Worldwide advertising revenues for the first three quarters of the year 2018 are as follows: in the first quarter revenues were 11.8 billion US dollars; in the second quarter revenues were 13 billion US dollars; in the third quarter revenues were 13.7 billion US dollars (Facebook Reports 2018). The investments into infrastructure and industrial hardware are following the expansion of core business. However, the scale of the investment into technology would be lower if the platforms had to pay for creative labour to produce and edit the content. The platform business model allows specialisation that enhances reversibility, whereas platforms' business strategies 
neglect the quality of content and the quality of reciprocity. The proliferation of fakenews, hate speech and racist content are prime examples of this.

Platforms, more than ever, shape global communication due to their monopoly positions. Alphabet (Google) is the largest media company, with the revenue of 82 billion Euros in 2017; Facebook is in 9th place with 25 billion Euros (Statista 2018b). Both companies are investing large sums of money to provide communication infrastructure worldwide. Alphabet's subsidiary Loon is even using high-altitude balloons, positioned in the stratosphere, to provide access to the most remote places on earth. Just recently, the company made a contract with Telkom Kenya (Wired 2018). The global perspective can most clearly show that the Internet is not a decentralised techno-social system, but a distributive one, where "concentrations of power are inevitable, and sometimes necessary" (Mathew 2016, 12). Distributive networks provide reversibility for users. This kind of reversibility does not necessarily imply reciprocity.

In the 1960s, David Lerner, a modernisation theorist, proposed an idea of "mass media spread in a direct and monotonic relationship with a rising level of industrial capacity" (2010/1963, 78). He concluded that mass media bring democracy and economic proliferation to the underdeveloped world. Modern industrial processes demand digitalisation, as well as the digitally-supported selling of goods. Productive audiences are spreading the consumerist ideology of the centre by themselves, whereas infrastructure is a required condition for such an expansion. In the developing world, ITU [International Telecommunication Union] (2016) figures show that infrastructure, in the form of fixed broadband connections, is built primarily for business purposes, whereas mobile broadband connections for cellular phones are already available to the end consumers. On a global scale, capital still has much space to colonise. ITU (2016) data show that $95 \%$ of the global population live in a geographical space covered by mobile-cellular network. Audiences-user markets and end-user product markets are ready to grow, because $53 \%$ of the world's population is still not using the Internet. Infrastructure and hardware enables reversibility - it opens communication channels for the public. However, investment into new channels is conditioned by the low composition of organic capital, which is a common characteristic of the global South. When investment opportunities arise, reciprocity in the form of exchange relations governs the selling of hardware, software and infrastructure.

As Noam $(2010,49)$ demonstrates, corporations that try to expand markets and nations that strive for economic development share the same goals of overcoming three kinds of digital gaps: a) telecommunication interactivity, b) Internet access, and c) e-commerce. When the first gap is closed by infrastructural investment, and the second by policies or advertising campaigns that promote Internet usage, soon the third is ready to close as well. The process brings ambiguous and contradictory consequences for both audiences and the public: "[c]losing the first two gaps therefore exacerbates the third gap by creating the highways and instrumentalities for rich countries to sell in poor countries" (Noam 2010, 50). Here contradictions of telecommunication connectivity come to the fore, being at the same time a necessary condition for participation in the global networked public sphere and detrimental for effective political freedom due to increased complexity of the international governance and fragmentation/normalisation of the global public sphere.

\section{Interactive Top-Down Communication Structure}

In principle, members of the public should all share a common discussion space in which particular interests are transformed towards consensus. Transformation of 
particular interests demands public dialogue and a "generalized support to the community as a whole" (Streeck 2016, 108). Not only that, but political diversification is in principle incompatible with market diversification: the former will always, even if it were acceptable to lead, lag behind market innovation, argues Streeck. Networked media resemble this friction. Platforms have "designed core architecture that governs the interaction possibilities" (Srnicek 2017, 27), which are not subdued to universalistic democratic principles but to market criteria, executed by algorithms. Now, entrenched political positions become shared backgrounds and ideological sub-centres of networks that productive audience are forming, whereas those who are dissimilar can gravitate to some other sub-centres. The public becomes fragmented, individualised, and homogenised by ideologically-similar content. Similarity implies congruence of political attitudes, identities, lifestyles, class positions and shared ideological worldviews. Similarity increases the potential of connecting with similar members of the public and lowers the probability of connecting with differing members of the public. Decades ago, Langholm had already based the notion of distance on the idea of similarity. Distance is a precondition for critical publicity. Similarity diminishes it:

"In measuring the spread of political participation, in terms of 'distance' from the center, it makes sense to understand 'distance' in terms of positions on, for instance, social 'background' dimensions such as education, occupation, income, property, as compared with the positions occupied by the central decision-makers on the same dimensions. The underlying principle of this concept of 'distance' would be similarity-dissimilarity with center" (Langholm 1971, 276).

Citizens who are distant from the centre of a given political system stay at the periphery. As in the times of classical mass media, they have no easy way to voice their dissent and criticism in dominant and consequently politically influential media or news portals. Their "freedom to achieve", as Bohman $(1997,327)$ would put it, is low. In contrast, citizens who are closer to the centre more easily persuade the gatekeepers to allow them access to the public sphere. Similarity with the centre presents no danger of disrupting the status quo. The congruence of one's political orientation with the dominant ideology preserves compliance with unequal positions of the centre and the periphery

Two main conceptualisations of fragmentation and individualisation of users occur frequently in contemporary scholarly writing. The first argues that fragmentation is closing the public into "filter bubbles" (Pariser 2011, 10). Filter bubbles encapsulate members with similar interests and form a polarised structure of, on the one hand, highly-informed and, on the other, poorly-informed segments of audiences (Gurevitch et al. 2009, 174; Prior 2007, 95). Sunstein (2001) sees the public enclosed into enclaves of similar opinions that are unable to transform their interests in accordance with consensual public opinion and in this way to achieve considerable political influence, which Habermasian theory of the public sphere envisions in principle.

On the other side of the fragmentation/individualisation debate, we find those who conceptualise a lively public sphere more in terms of antagonistic discourses. The general interest of the bourgeois public prevents problematisation of inequalities and the dominant liberal ideological position. Similar strategies also arise online, where "the 'mainstream' online discursive terrain is being structured by corporate portal and mass media sites promoting consumer discourse" (Dahlberg 2007, 840). This leads to "extreme fragmentation and homogenisation, participants framed as individualised 
consumers" (Dahlberg 2007, 840). By inclusion into a circular model of exchange, the periphery is becoming ideologically similar to the centre, facilitating dominant discourse through the production of depoliticised content. Both conceptualisations of fragmentation emphasise the political consequences of economic and ideological control that media are exerting through inclusion of productive audiences in exchange relations.

Similar demographics comprise more or less closed distributed networks with various intersections, but on the outside "the many watch the few" (Bauman 1998, 53), where "the many" means 'the mass'. Bauman critically assesses the interactivity of digital media and argues that we should rather speak about "an interactive one-way media", since "those who get access are allowed to make their choices within the frame set by suppliers" (Bauman 1998, 53). For example, in a research project about Digital Citizenship, in which the author of this article participated, the citizens who were interviewed have emphasised that communication of parliamentary political parties is monological and self-promotional despite the possible cooperative use of interactive social media, which grants political communication representative features (Sekloča 2016, 112).

Targets of corporate and political communication are valued according to their disposable income and compatibility of political interests. Where potentials for effective persuasion exist, "the availability and content of each message will have been shaped upon transmission to anticipate and replace the social interaction component of the two-step flow. This is the one-step flow of communication" (Bennett and Manheim 2006, 215). In political communication, successful persuasion may accrue additional votes and/or compliance to development/investment policies when considering the global space. At the same time, the periphery needs communication channels in order to be present in the (global) flows of information. Due to free market ideology and the popular conception of digital labour as play, the two entities reside without demonstrated friction, argues Fuchs (2014b, 124). Consequently, such an overlap of interests results in a forced symbiosis between the centre and the periphery.

Technology and content-based media, together with ICT companies, try to convert the peripheral "effective space", conceptualised as a space appraised in terms of its use value and its communicative potential, into a "created space". This conversion takes place under conditions of the centre's mode and form of production. Decades ago, Harvey argued that the idea of created space "involves the structuring and differentiation of space through the distribution of fixed capital investments" $(1993 / 1973,310)$. The more similar or ideologically close the public is to the powerful political and economic centre, the more easily the centre persuades the public to accept expansion strategies of the centre. One should not forget the flow of information and the transactions that sustain technology markets between the global North and South (Fuchs 2010; Noam 2010). Media and ICT companies direct their sales and investment activities towards particular targets (individuals, groups, nation states, and world regions), chosen by their statistically grounded profiles, disposable income, price of labour, the opportunities for investments, and ideological environment. The reciprocity of content, distribution and infrastructure between the centre and the periphery is conditioned by the organic composition of capital and the productivity race, which gives the social communication system the tendency to resemble the interactive top-down communication structure.

The interaction between the system and the lifeworld that sustains the (global) media and information market is hierarchical, whether in the dissemination of news, entertainment, advertising, or political communication. Nowadays, the idea of 
imperialism is somehow pushed aside by ideas about global-local symbiosis and the cheap production of content, to mention just a few ideologically-skewed arguments. However, the concept of media imperialism is still useful. Boyd-Barrett $(2010,150)$ argues that it should be conceptualised more multidimensionally, because of the proliferation of many forms and dimensions of communication: dependency on major news sources, production/processing relations between the clients, and cultural dimensions between imposed dominant and domestic indigenous cultures. In Galtung's structural theory of imperialism, top down, vertical and hierarchical communication is the major source of inequality. Centres are connected to each other; peripheries are connected to the centres, but not to each other. This form of communication resembles a top-down "feudal interaction structure", in which effective public communication between peripheries is missing, as also communication between periphery and other centres is missing (Galtung 1971, 89). Central nodes interact only with their end targets. On the other hand, media corporations use distributed forms of networks to manage the activities inside their own organisational structure and to interact with each other and with their customers (advertisers) on the industrial market of the global North. The communication form is horizontal and reciprocal in the search for 'synergies'. We should be aware of the Eurocentric description of Galtung's communication structure, because non-European territories have had other experiences. Moreover, exploitation of 'underdeveloped and immature' communities has also been present in the 'developed' North. Slavery in North America can be an example, writes Dussel $(1993,68)$. Thus, the term "feudal structure" (Galtung 1971, 89) only accentuates the form of the hierarchical communication structure that is similar to the feudal structure. This argumentation reminds us to consider centreperiphery relations denoting dominance universally, both in geographical and social space alike: "The problems initially posed as exclusive to the 'developing' regions of the world - poverty, disease, illiteracy, lack of basic economic skills, and information are now problems of large population groups within the 'developed' countries" (Mowlana 1997, 198). When we consider the organic composition of capital, the hierarchical division of the social space and the geographical space of the media and ICT markets conceptually overlap. The periphery in both developed and developing countries, and the periphery of the class structure, all have low organic composition of capital.

\section{The Power to Give}

The periphery does not only denote spaces outside the affluent global North: far from it. When we imagine the overlap of social and geographical peripheries that the systemic forces are colonising, the periphery designates the space in which the organic composition of capital is usually rising (due to capital investments) and where the political influence of the public is falling (due to promotional publicity). In these conditions, reversibility (interactivity), built into communication networks, maintains channels for the investment of constant capital and exploitation of labouring audiences. Only after the media industry in the fields of content production, distribution services and communication infrastructure establishes conditions that accelerate productivity is reciprocal participation in popular governance possible. Abstract exchange relations, played out on the market, substantiate reciprocity. Only a residual status is assigned to reciprocity of the public opinion formation processes.

Reversibility, controlled by algorithms and substantiated by the ideology of the free market, favours communication between members of the public that share similar interests. This kind of reversibility does not guarantee the reciprocal exchange of 
arguments and consequently the transformation of opposing interests towards consensus. Consequently, fragmentation and ideological homogenisation lowers the political influence of the public. In addition, social distance, i.e. ideological and socioeconomic similarity, conditions the relations between the centre and the periphery. The more the peripheral public becomes ideologically similar to the centre, the less it addresses detrimental consequences of capital expansion. The peripheral public is the centre of economic endeavours of network media and ICT corporations and the target of representational political communication. The notion of the "refeudalisation" of the public sphere is still a very up-to-date description of the presentational character of the centres of economic and political power 'before' the peripheral public, just as the king presents himself before the people in the medieval era (Habermas 1989a/1962, 1920).

The more the members of the public communicate, the more they become interesting for exploitation and the more they open opportunities for capital expansion due to network effects. The expansion and intensification of the exploitation of labouring audiences comes hand-in-hand with the commodification of social relations that are maintained by communication. The expansion of capital denotes the agglomeration of constant capital (user technology and investment into infrastructure) in social and geographical space. The exploitation of labouring audiences raises surplus value, whereas technical means of communication that audiences are using lower the whole amount of constant capital that would otherwise be required for media production. Productivity of the information and media sector can rise, because both strategies prevent profit rates from falling, whereas options for the investment into infrastructure are enhanced. Relations of production are centrally imposed, whereas means of production (labour, hardware and software, and infrastructure) are decentralised.

The opportunities for synergies between the counterinfluences and investment opportunities imposes a top-down communication structure. The media industry dictates conditions that delineate the structure of the communication system and the possibilities to produce and share content. Whereas production of amateur or professional content is decentralised, corporate platforms set the protocols of what content will be distributed, and to whom and where. Distribution is much more centralised than production. The new platform business models accelerated the socialisation of content production and the means of production; however, the distribution of wealth did not change. Under these conditions, productive audiences are induced to determine an optimal combination of constant and variable capital. Baudrillard said that the "power belongs to the one who can give and cannot be repaid. To give, and to do it in such a way that one is unable to repay, is to disrupt the exchange to your profit and to institute a monopoly" (Baudrillard 2003/1972, 281). The centre gives access to communication channels, the technology and the ideology of the dominating centre. The geographical and social periphery has nothing to give back to the centre but its living labour, personal data and compliance.

Contradictions between productivity and the enactment of democratic principles are theoretically substantiated in the critical politico-economic approaches to network public communication. Which antagonism in each of the contradictory tendencies prevails is an empirical question. Bigger sectors such as the finance and energy sectors take the lead in setting the parameters for distribution of profits and, by investment demand, dictate the pace of the information sector. In the future, a statistical comparison among the various sectors should be made to expose the relationships between them and the variations among their centres and peripheries. 


\section{References}

Baudrillard, Jean. 2003/1972. Requiem for the Media. In The New Media Reader, edited by Noah Wardrip-Fruin and Nick Montfort, 277-288. Cambridge, MA: The MIT Press.

Bauman, Zygmunt. 1998. Globalization: The Human Consequences. New York: Columbia University Press.

Benkler, Yochai. 2006. The Wealth of Networks: How Social Production Transforms Markets and Freedom. London: Yale University Press.

Bennett, W. Lance and Jarol B. Manheim. 2006. The One-Step Flow of Communication. Annals of the American Academy of Political and Social Science 608: 213-232.

Bohman, James. 1997. Deliberative Democracy and Effective Social Freedom: Capabilities, Resources and Opportunities. In Deliberative Democracy, edited by James Bohman and William Rehg, 321-348. Cambridge: MIT.

Boyd-Barrett. 2010. Media Imperialism Reformulated. In International Communication: A Reader, edited by Daya K. Kishan, 139-153. New York: Routledge.

Brecht, Bertolt. 1932. The Radio as an Apparatus of Communication. Bjitter des Hessischen. Accessed June 20, 2017.

http://sodacity.net/system/files/Bertolt Brecht The Radio as an Apparatus of Commun ication.pdf

Carchedi, Guglielmo and Michael Roberts. 2013. A Critique of Heinrich's 'Crisis Theory, the Law of the Tendency of the Profit Rate to Fall, and Marx's Studies in the 1870s'". Monthly Review. Accessed November 3, 2018. http://monthlyreview.org/commentary/critiqueheinrichs-crisis-theory-law-tendency-profit-rate-fall-marxs-studies-1870s/

Castells, Manuel. 2009. Communication Power. Oxford: University Press.

Castells, Manuel. 1996. The Rise of the Network Society. Oxford: Blackwell.

Curran, James. 2003. Media and Power. London: Routledge.

Curran, James. 2000. Rethinking media and democracy. In Mass media and society, edited by James Curran and Michael Gurevitch, 120-154. London: Arnold.

Dahlberg, Lincoln. 2007. Rethinking the Fragmentation of the Cyberpublic: From Consensus to Contestation. New Media \& Society 9 (5): 827-847.

Data Center Knowledge. 2018. Facebook data Center FAQ. Accessed September 5, 2018. https://www.datacenterknowledge.com/data-center-faqs/facebook-data-center-faq-page-3

Dussel, Enrique. 1993. Eurocentrism and Modernity (Introduction to the Frankfurt Lectures). boundary 2, 30 (3): 65-76.

Enzensberger, Hans Magnus. 2003/1970. Constituents of a Theory of the Media. In The New Media Reader, edited by Noah Wardrip-Fruin and Nick Montfort, 259-276. Cambridge, MA: The MIT Press.

Facebook Reports. 2018. Quarterly Earnings. Accessed November 3, 2018. https://investor.fb.com/financials/?section=quarterlyearnings

Fuchs, Christian. 2017. Facebook. In Global media Giants, edited by Benjamin J. Birkibine, Rodrigo Gómez and Janet Wasko, 428-444. New York: Routledge.

Fuchs, Christian. 2014a. Social Media: A critical introduction. London: Sage.

Fuchs, Christian. 2014b. Digital Labour and Karl Marx. New York: Routledge.

Fuchs, Christian. 2012. The Political Economy of Privacy on Facebook. Television \& New Media 13 (2): 139-159.

Fuchs, Christian. 2010. New Imperialism: Information and media imperialism? Global Media and Communication 6 (1): 33-60.

Galloway, Alexander R. 2004. Protocol: How Control Exists after Decentralization. Cambridge, MA: The MIT Press.

Galtung, Johan. 1971. A Structural Theory of Imperialism. Journal of Peace Research 8 (2): 81-117.

Gandy, Oscar H. 1982. Beyond Agenda Setting: Information Subsidies and Public Policy. Norwood: ABLEX Publishing Co. 
Garnham, Nicholas. 1990. Capitalism and Communication: Global Culture and the Economics of Information. London: Sage.

Gurevitch, Michael, Stephen Coleman and Jay G. Blumler. 2009. Political Communication: Old and New Media Relationships. The Annals of the American Academy of Political and Social Science 625: 164-181.

Habermas, Jürgen. 2009. Europe: The Faltering Project. Cambridge: Polity Press.

Habermas, Jürgen. 1989a/1962. Strukturne spremembe javnosti. Ljubljana: ŠKUC.

Habermas, Jurgen. 1989b. The Theory of Communicative Action. Volume Two: Lifeworld and System: A Critique of Functionalist Reason. Boston: Beacon Press.

Harvey, David. 2014. Crisis Theory and the Falling Rate of Profit [Draft]. Accessed November 3, 2018. https://thenextrecession.files.wordpress.com/2014/12/harvey-onItrpf.pdf

Harvey, David. 1993/1973. Social Justice and the City. Oxford: Blackwell.

Heinrich, Michael. 2013. "Crisis Theory, the Law of the Tendency of the Profit Rate to Fall, and Marx's Studies in the 1870s". Monthly Review 64 (11). Accessed November 3, 2018.

https://monthlyreview.org/2013/04/01/crisis-theory-the-law-of-the-tendency-of-the-profit-rateto-fall-and-marxs-studies-in-the-1870s/

International Telecommunication Union. 2016. ICT Facts and Figures 2016. Geneva: International Telecommunication Union. Accessed May 1, 2017. https://www.itu.int/en/ITU-D/Statistics/Documents/facts/ICTFactsFigures2016.pdf

Jenkins, Henry. 2006. Convergence Culture. New York: New York University Press.

Kliman, Andrew. 2015. Harvey Versus Marx On Capitalism's Crisis Part 1: Getting Marx Wrong. New Left Project.

Kliman, Andrew. 2011. The Failure of Capitalist Production: Underlying Causes of the Great Recession. London: Pluto Press.

Kliman, Andrew. 2007. Reclaiming Marx's "Capital": A Refutation of the Myth of Inconsistency. Lanham: Lexington Books.

Kliman, Andrew, Alan Freeman, Nick Potts, Alexey Gusev and Brendan Cooney. 2013. The Unmaking of Marx's Capital: Heinrich's Attempt to Eliminate Marx's Crisis Theory. Social Science Research Network Working Papers Series: 1-20.

Langholm, Sivert. 1971. On the Concepts of Center and Periphery. Journal of Peace Research 8 (3/4): 273-278.

Lerner, Daniel. 2010/1963. Toward Communication Theory of Modernization: A Set of Considerations. In International Communication: A Reader, edited by Daya K. Kishan, 7388. New York: Routledge.

Marx, Karl. 1993/1939. Grundrisse. London: Penguin books.

Marx, Karl. 1948/1894. Kapital III. Zagreb: Kultura.

Marx, Karl. 1947/1867. Kapital I. Zagreb: Kultura.

Mathew, Ashwin. 2016. The Myth of the Decentralised Internet. Internet Policy Review 5 (3): 1-16.

McKenzie, Nigel, 1977. Centre and Periphery: The Marriage of Two Minds. Acta Sociologica, 20 (1): 55-74.

Mills, Charles Wright. 1965. Elita oblasti. Ljubljana: DZS.

Mowlana, Hamid. 1997. Global Information and World Communication : New Frontiers in International Relations. London: SAGE.

Möller, Johanna and M. Bjørn von Rimscha. 2017. (De)Centralization of the Global Informational Ecosystem. Media and Communication 5 (3): 37-48.

Noam, Eli. 2010. Overcoming the Three Digital Divides. In International Communication: $A$ Reader, edited by Daya K. Kishan, 48-55. New York: Routledge.

Pariser, Eli. 2011. The Filter Bubble. New York: The Penguin Press.

Prior, Markus. 2007. Post-Broadcast Democracy: How Media Choice Increases Inequality in Political Involvement and Polarizes Elections. New York: Cambridge University Press. 
Roberts, Michael. 2014. Monomania and Crisis Theory - a reply to David Harvey. Accessed November 3, 2018. https://thenextrecession.files.wordpress.com/2014/12/reply-toharvey.pdf

Samuelson, Paul A. 1971. Understanding the Marxian Notion of Exploitation: A Summary of the So-Called Transformation Problem Between Marxian Values and Competitive Prices. Journal of Economic Literature 9 (2): 399-431.

Sekloča, Peter. 2016. Political Effectiveness of Digital Citizens: Communication in the Structured Hierarchies of Power. Annales, Series historia et sociologia 26 (1): 107-118.

Sekloča, Peter. 2015. The Law of the Tendency of the Rate of Profit to Fall and the End User Communication Technology. Journal for the Critique of Science 259: 131-142.

Smythe, Dallas. 1995. On the Audience Commodity and its Work. In Approaches to Media: A Reader, edited by Oliver Boyd-Barrett and Chris Newbold, 153-163. London: Arnold.

Srnicek, Nick. 2017. Platform Capitalism. Cambridge: Polity Press.

Statista. 2018a. Facebook's U.S. and non-U.S. advertising revenue from 2014 to 2018 (in billion U.S. dollars). Accessed September 7, 2018. https://www.statista.com/statistics/544001/facebooks-advertising-revenue-worldwide-usa/

Statista. 2018b. Largest media companies worldwide 2017. Accessed November 3, 2018. https://www.statista.com/statistics/272469/largest-media-companies-worldwide/

Streeck, Wolfgang. 2016. How Will Capitalism End? London: Verso.

Sunstein. Caas. 2001. Republic.com. Princeton: Princeton University Press.

Sverdlik, Yevgeniy. 2018. Facebook to Build the Largest Hyperscale Data Center Singapore Has Ever Seen. Data Center Knowledge. Accessed November 3, 2018. https://www.datacenterknowledge.com/facebook/facebook-build-largest-hyperscale-datacenter-singapore-has-ever-seen

Thussu, Daya K. 2005. The Marketization of Global Communication. Javnost-The Public 12 (3): 47-60.

Van Cuilenburg, Jan. 1999. On Competition, Access and Diversity in Media, Old and New: Some Remarks for Communication Policy in the Information Age. New Media \& Society 1 (2): 183-207.

Wired. 2018. Loon's Internet-Slinging Balloons Are Headed to Work Over Kenya. Accessed September 1, 2018. https://www.wired.com/story/loon-internet-balloons-kenya-googlealphabet-x/

\section{About the Author}

\section{Peter Sekloča}

Peter Sekloča is an associate professor at the Faculty of Humanities, department of Communication and Media, University of Primorska, Slovenia. His main research fields are public sphere theory, political economy of communication, and international communication. Examples of publications are Contradictions of Media Production and the Heterogeneity of Products, in Javnost - The Public (2015) and Political Effectiveness of Digital Citizens: Communication in the Structured Hierarchies of Power, in Annales (2016). 